\title{
HAMZAH FANSURI DAN DOKTRIN WAHDAT AL-WUJUD DI NUSANTARA
}

\author{
Rasuki \\ Dosen STIT Al-Karimiyyah
}

\begin{abstract}
Tokoh sufi Nusantara yang meninggalkan beberapa karya, salah satunya adalah Hamzah fansuri. Kontroversi doktrin Wahdat al-Wujud pernah diadopsi dari tokoh sufi besar, Ibn 'Arabi. Doktrin tasawuf Hamzah Fansuri selain mendapat sambuatan banyak kalangan-terlabih dikalangan para muridnya-juga mendapat krirtik dari sebagian kalangan muslim lainnya. Sebagai doktrin dalam khazanah dunia tasawuf Nusantara, Wahdat alWujud Hamzah Fansuri sebagai menifastasi dan kelanjutan dari gagasan Sufi terkemuka, Ibn 'Arabi yang dipopulerkan oleh salah muridnya. Wahdat alWujud Hamzah Fansuri sebagai faham yang mengajarkan bahwa keesahan Tuhan sama sekali tidak bertentangan dengan konsep penampakan pengetahuan Tuhan yang sangat variatif dalam kehidupan nyata. Dari-Nya, dalam dunia nyata terlahir penampakan dhahir dan batin dari Wujud yang Satu, yakni Tuhan.
\end{abstract}

Keywords: Wahdat al-Wujud, Hamzah fansuri, Ibn 'Arabi

\section{Pendahuluan}

Gagasan Wahdat al-Wujud-sebagai salah satu doktirn ilmu tasawuf-Hamzah Fansuri menuai kontroversi. Sebagian kalangan muslim (sufi) mengafirmasi gagasan tersebut, dan sebagian lagi menolak dengan berbagai argumen. Wahdat al-Wujud tak hanya diterima ada diamini dikalangan masyarakat muslim, ia juga 


\section{Rasuki}

dihujat sekaligus yang diasumsikan sebagai doktrin yang dapat membahayakan (menyesatkan) akidah umat Islam.

Di tengah kontroversi wacana ajararan, selain yang mengafirmasi dan yang menegasi, Wahdat al-Wujud Fansuri tidak hanya sebatas menjadi buah bibir semata, akan tetapi ia juga menjadi praksis amaliyah yang terus dikembangkan dan disebarkan-luaskan kepada pengikut setianya (atau muridnya) ditengah kontroversinya.

Di Nusantara, Sumatera Utara persisnya, Wahdat al-Wujud yang pernah di gagas Ibn 'Arabi-dan dipopulerkan oleh salah satu muridnya-menemukan pertalian dengan Wahdat al-Wujud Hamzah Fansuri, salah satu tokoh sufi besar yang cukup berpengaruh di masanya. Berkat keahlian Fansuri pada dunia tasawuf (tarikat), banyak murid yang berguru kepadanya, disamping banyak tulisan yang ditinggalkan dari buah kontemplasi tasawuf tentang faham Wahdat al-Wujudnya.

Dalam tulisan ini, Wahdat al-Wujud Hamzah Fansuri selain memiliki mata rantai persambungan kepada Ibn 'Arabi, salah satu tokoh sufi asal Persia, patut dibincang kembali mengingat Wahdat al-Wujud Hamzah Fansuri merupakan kekayaan khazanah pemikiran tasawuf di Nusantara. Mengingat pentingnya gagasan tersebut, mengungkap kembali tasawuf warisan Hamzah Fansuri merupakan suatu keniscayaan. Hal ini sebagai wujud penghargaan atas rintisan awal Hamzah Fansuri dalam menebarkan faham wahdat al-wujud di Nusantara.

\section{Biografi Hamzah Fansuri}

Tidak banyak sejarawan Indonesia yang menulis tentang riwayat hidup para ulama' sufi Indonesia, termasuk diantaranya adalah riwayat Hamzah Fansuri, sufi besar yang lahir di Sumatera Utara. Fansuri-sebagaimana sebagian sufi lain-tidak menceritakan tentang riwayat hidup dalam karya-karya intelektualnya. Dengan faktor ini sehingga untuk mengenalnya para ahli/peneliti mengalami banyak kesulitan, bahkan tidak jarang terjadi silang pendapat mengenai sejarah kiprah kehidupannya.

Fansuri kecil belum dapat dipastikan tanggal lahir dan wafatnya. Sebagian ahli menyebut bahwa ia hidup pada akhir abad ke-17, sedangkan al-Attas lebih menyakini Fansuri hidup pada awal abad ke-17 M. Menurut Miftah Arifin dengan mengutip pendapat Drewes dan Brakel, menyebutkan bahwa Fansuri hidup di akhir abad ke-16 M. Hal itu dibuktikan dengan mengacu pada ajaran "martabat tujuh" yang pernah disebar-luaskan salah satu muridnya, Syamsuddin Pasai di 
awal abad ke17. ${ }^{1}$ Sedangkan sebagian kalangan yang meyakini hidup Fansuri di abad ke-17 M. mengacu pada fakta adanya kitab Tuhfah di awal abad itu. Maka kedua perbedaan tentang riwayat hidup Fansuri memiliki acuan sendiri berdasar kolerasi hidupnya baik dengan mengacu pada teks-teks karyanya yang dijadikan rujukan dan yang ditafsir maupun periode waktu dimana ajaran Fansuri disebarluaskan oleh generasi berikutnya.

Hal yang sama terjadi juga pada tahun kelahiran dan meninggalnya. Kraemer menduga bahwa Fansuri hidup sampai pada tahun $1636 \mathrm{M}$, menurut kesaksian Barginsky, Fansuri diyakini hidup sampai tahun $1621 \mathrm{M}$, dengan mendasarkan pada catatan sebagian peneliti dari Eropa. Sedangkan menurut Winnsedt, Hamzah Fansuri wafat pada tahun $1630 \mathrm{M}$. bukan pada tahun $1636 \mathrm{M}$. sebagaimana disebut oleh Kraemer. ${ }^{2}$

Tentang tahun kelahiran dan kematian Fansuri tidak dicapai kesepatakan pasti diantara para ahli yang melakukan penelitian terhadap karya intelektual Hamzah Fansuri. Tapi satu hal pasti adalah bahwa Fansuri pernah merantau kebeberapa negara, sebagaimana yang pernah terungkap dalam salah satu bait syairnya. Kesenangannya hidup merantau menjadi bukti kuat atas wafatnya di kota Makkah, salah satu kota yang menjadi tempat perantauannya. Bukti tersebut sebagaimana Guilliot sebutkan, terdapat pada "inkripsi" batu tulisan nisan atau makam kuburannya di Makkah yang bertuliskan nama langkap Hamzah ibn Abdillah al-Fansuri. ${ }^{3}$

Namun dalam cerita, nama Hamzah Fansuri sendiri menurut sebagian tidak diberikan oleh kedua orang tuanya. Nama tersebut diberikan oleh pelaut yang melakukan perdagangan yang pernah singgah ke pantai Barat Sumatera Utara. Cerita tersebut diperkuat-selain sulitnya data catatan riwayat hidupnya-oleh nasib dimasa kecilnya yang telah menyandang status piatu, selain juga berlatar dari keluarga kecil, masyarakat biasa. ${ }^{4}$

Karena dari latar keluarga kecil, Fansuri memiliki tekat kuat untuk merubah nasib dinegeri perantauan dengan mengembara ke beberapa negara untuk mendapat harta. Sehingga banyak negara yang pernah disinggahi seperti Baghdad, Kudus. Di Baghdad ia pernah menjadi pengikut aliran tarekat yang cukup banyak

\footnotetext{
${ }^{1}$ Miftah Arifin, SUFI NUSANTARA: Biografi, Karya Intelektual \& Pemikiran Tasawuf, (Jogjakarta: AR-RUZZ MEDIA, 2013), 30

${ }^{2}$ Alwi Shihab, ISLAM SUFISTIK: "Islam Pertama" dan Pengaruhnya hingga Kini di Indonesia, (Bandung: Penerbit Mizan, 2001), 118

${ }^{3}$ Claude Guillot dan Ludvik Kalus, Batu Nisan Hamzah Fansuri, (Jakarta: Depbudpar, 2007), 3-24

${ }^{4}$ Miftah Arifin, SUFI NUSANTARA, 30, 33
}

Kariman, Volume 06, Nomor 02, Desember 2018|215 


\section{Rasuki}

pengikutnya, yakni Qadiriyah. Tidak puas dengan pengalaman di Baghdad, ia melanjutkan perantauannya ke Makkah seperti dalam pengakuan di salah satu bait syairnya, dengan tujuan untuk mencari Tuhan di tempat suci, Baitul Ka'bah. ${ }^{5}$

Dari pengalaman menapaki beberapa negara dan ketertarikannya dengan dunia tasawuf hingga menjadi pengikut tarekat yang diakuinya untuk mencari Tuhan, dapat difahami : pertama, bahwa Fansuri adalah sosok pribadi mandiri yang terobsesi ingin merubah nasibnya (miskin) dengan cara bekerja di negeri orang untuk mendaptkan harta dari jerih payah sendiri. Meski pada akhirnya, ia tidak dikenal sebagai seorang yang sukses menjadi hartawan. Tetapi sebaliknya, harta yang dicari hanya sebatas sarana ia dalam mencari ilmu.

Kedua, Fansuri adalah pribadi yang sedang mencari jati diri, pribadi yang haus akan ketenangan batin sehingga pencarian Tuhan terobati dengan cara mendekati Tuhan melalui jalur ilmu tasawuf, disiplin ilmu yang lebih mengedepankan kesucian hati/batin untuk selalu dekat dengan sang khaliq dari pada mengasah akal pikiran (rasio) semata.

Sehingga di perantaua itulah ia bersentuhan dan berkenalan dengan pemikiran para tokoh sufi besar dan terkenal dari Persia. Dapat di sebutkan diantaranya, alBusthami, Fariduddin al-Attar, al-Hallaj, al-Junaidi, al-Ghazali, Jalaluddin Rumi dan Ibn Arabi. Perjumpaanya dengan karya pemikiran para tokoh sufi cukup membekas dalam pemikiran tasawufnya dikemudian hari. Sehingga Fansuri kemudian mengembangkan atau lebih tepatnya mengamalkan dan mengajarkan doktrin Wahdat al-Wujud yang dirintis oleh Ibn 'Arabi tentang "kesatuan wujud".

\section{Beberapa Karya Hamzah Fansuri}

Sebagai ulama' yang ahli dalam bidang tasawuf, Fansuri meninggalkan relatif banyak karya tulis terutama dalam bentuk bahasa Melayu. Dalam dunia tasawuf yang digelutinya, serta pengalaman yang banyak dialaminya kemudian terbingkai dalam beberapa bukunya hingga kini masih ada baik dalam bentu syair puisi dan dalam bentuk prosa.

Hamzah Fansuri termasuk ahli sufi yang cukup produktif. Banyak tulisan baik dalam bentuk syair atau puisi yang berserakan disamping dalam bentuk buku utuh. Diantara tulisan Hamzah Fansuri yang masih tercatat lengkap hingga sekarang terdapat tiga buku, sebagaimana disebutkan Alwi Shihab dan Abdul

\footnotetext{
${ }^{5}$ Drewes and Brakel, The poems of Hamzah Fansuri, (Dordrecht-Hollend: Foris Publication, 1986), 108. Meski Hamzah Fansuuri pernah berpindah-pindah tempat dari satu negara ke negara lain, tidak di jelaskan dalam buku ini berapa lama Fansuri bermukim pada masing-masing tempat yang disinggahinya.
} 
Hadi W. M. Sedangkan dalam buku Sufi Nusantara, Miftah Arifin menyebut beberapa buku tulisan Hamzah Fansuri diantaranya:

1. Asrar al-Arifin (Rahasia Ahli Makrifat), kitab yang menjelaskan tentang pokok-pokok ajaran kaitan dengan doktrin Wahdat al-Wujud. Kitab yang mengurai panjang lebar tentang metafisikan wujudiyah, tentang sifat-sifat Tuhan, posisi-Nya yang diibaratkan lautan luas dan dalam. Dalam kitab ini juga banyak di singgung term-term asing khusus yang cukup sulit yang tak mudah difahami terutama oleh kalangan masyarakat awam pada umumnya. ${ }^{6}$

2. Syarab al-Asyiqin (Minuman Orang Berahi), yang sering juga disebut dengan Zinat al-Muwahidin sebagai kitab syarah. Kitab ini merupakan karya Hamzah Fansuri pertama yang mengulas tentang risalah tasawuf, sekaligus berisi tentang jawaban atas pertanyaan-pertanyaan musykil terkait dengan masalah al-A'yan al-Thabitah (tasawuf Wujudiyah) dan cara mencapai makrifat. ${ }^{7}$ Menurut Miftah Arifin, kitab ini mengupasa tentang jalan-jalan yang harus ditempuh dalam mengarungi dunia tasawuf, dengan menjelaskan tahapan-tahapan dalam ilmu suluk dari awal, dengan uraian syari'at, tariqat, hakekat dan ma'rifat. ${ }^{8}$

3. Al-Muntahi. Dalam kitab ini Fansuri menulis dalam bentuk prosa yang di dalamnya membahas doktrin Wahdat al-Wujud dengan banyak mengutip pendapat-pendapat Ibn 'Arabi.

Sedangkan Miftah Arifin tidak hanya menyebut tiga (3) karya Hamzah Fansuri sebagaimana di atas. Miftah menambahkan dua kitab lain tulisan Fansuri yang ditinggalkan dalam bentuk syair diantaranya: ${ }^{9}$

4. Syair Perahu. Sebuah risalah tentang dasar-dasar ajaran tasawuf dengan menggunakan ungkapan-ungkapan perahu sebagai simbol kehidupan.

5. Syair Burung Pinggai. Dalam risalah ini Fansuri menggambarkan tentang proses fana dan baqa' yang harus dilalui seseorang untuk menuju kesatuan wujud (?). ${ }^{10}$ Dalam karyanya ini terang Miftah Arifin, Fansuri mendapat inspirasi langsung dari tulisan Fariduddin Aththar dalam kitab Manthiq Attair.

\footnotetext{
${ }^{6}$ Ibid, 35

${ }^{7}$ Adbul Hadi, Tasawuf Yang Tertindas, (Jakarta: Paramadina, 2001), 135, 147

${ }^{8}$ Miftah Arifin, Sufi Nusantara, 35

${ }^{9}$ Ibid, 35

${ }^{10}$ Agar tidak terjadi bias dalam pemahaman dengan maksud Hamzah Fansuri tentang doktrin Wahdat alWujudnya, Fansuri tidak menyamakan posisi antara Tuhan dengan makhluk (manusia) sebagaimana doktrin ittihad dan hulul .
} 


\section{Doktrin Wahdat al-Wujud}

Banyak kalangan menilai ajaran wujudiyah Hamzah Fansuri sebagai babakan baru ajaran Wahdat al-Wujud dalam diskursus tasawuf di Nusantara. Sebab tak satupan para sufi sebelumnya menyebarkan doktrin Wahdat al-Wujud di Nusantara. Doktrin Islam yang diapresiasi masyarakat setempat lebih berorientasi fiqh dari pada tasawuf. Karenanya, faham Wahdat al-Wujud di tangan Fansuri sebagai lanjutan dari ajaran Wahdat al-Wujud Ibn 'Arabi. Artinya, Hamzah Fansuri adalah sufi Islam awal yang mengenalkan dalam pikiran masyarakat Indonesia tentang doktrin wujudiyah Ibn 'Arabi.

Dalam sejarahnya, istilah Wahdat al-Wujud, Ibn 'Arabi selalu menjadi rujukan utama, seolah sebagai penggagas pertama istilah Wahdat al-Wujud. Akan tetapi istilah Wahdat al-Wujud sesungguhnya pertama kali diperkenalkan oleh Sadr alDin al-Qunawi (w. 1274) murid Ibn 'Arabi yang mengatakan bahwa ke Esahan Tuhan tidak bertentangan dengan penampakan pengetahuan-Nya yang sangat bervariasi. Tuhan sebagai Wujud tunggal satu-satunya yang tidak berubah. Justru yang berubah dari satu menjadi banyak terdapat pada wujud selain-Nya. Faham Wahdat al-Wujud selanjutnya terus dipopulerkan oleh murid-murid Ibn 'Arabi selain al-Qunawi, seperti Sa'id al-Din al-Farghani (w. 1301), Mu'ayyid al-Din alJandi (w. 1219) dan yang lainnya. ${ }^{11}$

Menurut Ibn "Arabi penjelasan tentang Tuhan sebagai "Yang Satu" hanya berada pada pembicaraan dalam sistem metafisika. Metafisika sebagai disiplin ilmu yang membahas tentang obyek dibalik fisika dengan mengupas hakekat ontologi, yang ada (Being). Keberadaan being Yang Satu adalah Wujud muhith (meliputi segala sesuatu) dan merupakan panggung terakhir dari segala kewujudan. Selain itu, bagi Ibn "Arabi, Tuhan sebagai "Wujud" disebut pula kesadaran yang meliputi segala sesuatu dijagat alam raya. Begitu pula ketika menyebut keindahan, Ibn 'Arabi menyebut Tuhan sebagai Cinta. ${ }^{12}$ Artinya, Tuhan dan keindahan menjadi tak terpisahkan tersebab dengan adanya cinta sebagai bagian yang tak terpisahkan pula, seperti yang dirasakan para sufi dalam pengalaman mistiknya. ${ }^{13}$

Keindahan Tuhan sebagai Wujud yang Satu adalah sumber dari segala keindahan lainnya, baik dalam bentuk ruhani maupun intelektual. Akan tetapi

\footnotetext{
${ }^{11}$ Abdul Hadi W. M., Tasawuf Yang Tertindas, 160

${ }^{12}$ Ibid, 55

${ }^{13}$ Robi'ah al-Adawiyah sufi perempuan yang menggagas konsep Mahabbah kepada Tuhan dengan meningalkan semua kesenangan duniawi dan lainnya, disebabkan oleh cintanya kepada Tuhan, sehingga ia tidak sempat mencintai yang lainnya.
}

218 | Kariman, Volume 06, Nomor 01, Desember 2018 
keindahan Tuhan tidak terikat dengan hal tertentu saja, melainkan keindahan-Nya bebas dari segala rupa maupun bentuk. Maka yang dimaksud Ibn 'Arabi dengan Wujud bukanlah wujud yang mengambil rupa dan bentuk nyata, akan tetapi penampakan Tuhan melalui Sifat-sifat-Nya yang kewujudannya hanya dapat diselami dengan penglihatan batin. Penglihatan batin hanya dapat dirasakan langsung oleh keberadaan cinta di dalam hati. ${ }^{14}$ Hal demikian sebagaimana dalam pengalaman mistik seorang sufi, yang hanya menyaksikan bahwa Wujud hakiki adalah satu, sedangkan wujud lainnya lenyap disingkirkan oleh cinta dan kefanaan seseorang. ${ }^{15}$

Sedangkan kata Wujud menurut Ibn 'Arabi yaitu wujud (ada) hakiki yang hanya dikenakan kepada Tuhan yang satu, sedangkan wujud yang dimiliki makhluk bukan wujud hakiki sebagaimana Tuhan. Keberadaan Wujud Tuhan bersifat mutlak yang berbeda dengan wujud makhluk yang bersifat majazi (ibarat). Maka, bagi Ibn 'Arabi, Tuhan dan makhluk tidak memiliki kesamaan, antara Tuhan dengan alam tidak ada keserupaan. ${ }^{16}$

Hal demikian juga dijelaskan oleh Hamzah Fansuri, di mana ia tidak menyamakan Tuhan sebagai Wujud mutlak dengan alam sebagai kiasan belaka. Kemudian Famsuri menganalogkan antara hubungan Tuhan dan alam tersebut dengan pohon dan biji yang menjadi bibitnya. Perbedaan antara dua benda antara biji dan pohon jelas berbeda, akan tetapi sesungguhnya secra hakekat (esensi) keduanya adalah satu, ${ }^{17}$ di mana esensi pohan dengan biji bermula dari hakekat yang satu untuk kemudian berbeda, yang berasal dari keadaan yang satu, yakni pohon.

Selain yang satu (Tuhan), semua keberadaan bermula dari ketiadaan. Alam dan seisinya baik yang tampak pada kita maupun yang tak tampak (ghaib) seperti 'Asy, surga dan sejenis lainnya (dunia metafisik) bermula dari ketiadaan. Alam adalah entitas yang keberadaannya bermula dari ketiadaan, berubah menjadi ada, dan adanya karena sesuatu yang mengadakan (Tuhan). Tuhan sebagai Wujud pertama dan sempurna, darinya wujud lain menjadi ada. Dengan kata lain, Tuhan selain wujud pertama adalah wujud penggerak utama akan adanya wujud lainnya yang bermula dari ketiadaan menjadi ada (Wujud). Sebab, jelas Ibn 'Arabi, sesungguhnya adalah pergerakan paling dasar dan utama ialah bermula dari

\footnotetext{
${ }^{14}$ Abdul Hadi W. M., Tasawuf Yang Tertindas, 58

${ }^{15}$ Ibid, 44

${ }^{16}$ Ibid, 162

${ }^{17}$ Oman Fathurahman, Tanbih al-Masyi Menyoal Wahdatul Wujud: Kasus Abdurrauf Singkel di Aceh Abad 17, (Bandung: Mizan, 1999), 53
} 


\section{Rasuki}

pergerakan dunia dari tiada ('adam) lalu dari kesenyapannya ia melangkah menuju keadaan mempunyai wujud. ${ }^{18}$

Yang mengadakan sebelumnya (dahulu/Qadim) inilah yang disebut Fansuri dengan Dzat yang Satu yang Pertama yang ada dengan dirinya sendiri, tidak tergantung pada lainnya. Yang pertama atau yang dahulu oleh Fansuri disebut dengan Huwa (Tuhan), seperti dijelaskan dalam kitab Asra al-'Arifin bahwa :

.....ya'ni tatkala bumi dan langit belum ada. 'Arsh dan Kursi belum ada, shurga dan neraka belum ada-semesta sekalian (alam) pun belum ada, apa jua yang pertama? ya'ni Yang Pertama Dhat Semata, Sendiri-Nya, tiada dengan Sifat, dan tiada dengan Asma-Nya, itulah Yang Pertama. Adapan nama Dhat itu Huwa". ${ }^{19}$

Sedangkan Wujud (ada) kedua setelah Wujud Pertama adalah Muhammad (nur Muhammad). Muhamamad adalah wujud kedua setelah Wujud Pertama, kemudian mengadakan wujud-wujud lainnya, alam dan seisinya. Dengan kata lain, wujud pertama menyebabkan (memancarkan) wujud kedua yaitu cahaya Muhammad. Tegasnya, cahaya yang pertama memancar dari hakekat Tuhan, menurut Fansuri adalah cahaya Muhammad. ${ }^{20}$ Dengan demikian dapat difahami bahwa wujud lain baru menjadi ada setelah cahaya Muhammad menjadi Wujud (majas/tidak hakiki). Penegasan Fansuri merujuk pada dua Hatis Qudsi yang cukup populer dikalangan sufi yang artinya:

"kalau tidak karenamu (Muhammad), niscaya Aku tak menciptakan alam", dan "Aku menciptakan semua karena engkau (Muhammad) dan Aku mencipta engkau karena Aku". ${ }^{21}$

Apa yang dimaksud dengan cahaya Muhammad atau wujud kedua yang dimaksud Hamzah Fansuri? Nur Muhammad menurutnya adalah pengetahuan Tuhan yang meliputi seluruh yang ada dan yang masih berada dalam alam ghaib. Sehingga pula Nur bagi Fansuri juga bermakna informasi, sebab sesuatu yang memancar pada sekelilingnya dan dapat di tangkap oleh keadaan (panca indra manusia), sehingga karena darinya (nur) dapat diketahui sebab sebagai informasi. Ringkasnya, bagi Fansuri, Nur bermakna ilmu atau pengetahuan, dan

\footnotetext{
${ }^{18}$ Abdul Hadi W. M., Tasawuf Yang tertindas, 57

${ }^{19}$ Oman Fathurahman, Tanbih al-Masyi, 39

${ }^{20}$ Ibid, 38

${ }^{21}$ Alwi Shihab, ISLAM SUFISTIK, 134
} 
pengetahuan identik dengan informasi, di mana informasi dalam bentuk lainnya adalah pengetahuan. Ilmu atau pengetahuan Tuhan oleh Fansuri disamakan dengan "al-haqiqah al-Muhammadiyah" (hakekat Muhammad). ${ }^{22}$

Pemaknaan Fansuri tersebut tidak hanya sebatas mengikuti kemampuan akal semata dalam menjelaskan maknanya dengan memahami dan menganalisa, akan tetapi ia juga merujuk pada salah satu Hadis Qudsi yang populer dan banyak disebut para sufi. Hadis dimaksud berbunyi:"Aku (Allah) adalah simpanan yang tersembunyi, maka Aku ingin diketahui, lalu Aku ciptakan makhluk dan dengan makhluk itu kenalilah $A k u$ ". Suatu rujukan primer dalam agama yang kemudian bagi Fansuri dimaknai sebagai wujud pertama eksis dan sekaligus pengada lainnya.

Jika Tuhan sebagai Wujud Pertama sekaligus sebagai pengada bagi wujud lainnya, apakah ini menandaskan adanya kesamaan antara pencipta dan yang dicipta? Dengan kata lain, Hamzah Fansuri sedang menyamakan posisi Tuhan dengan hambanya? Dalam pengakuannya ia hanya sebatas mentamsil Tuhan dengan mengibaratkan "Bahr al-'Amiq" (lautan sangat dalam). Tamsil yang dimaksud terkait dengan ke-Ada-an Tuhan, yaitu pekerjaan-Nya dalam mencipta yang tidak berkesudahan bahkan tidak ada yang menandingi. Ini jelas berbeda dengan posisi makhluk (manusia), yang diibaratkan dengan buih ombak. Posisinya sangat kecil tidak ada apa-apanya dibandingkan dengan keagungan dan keluasan ilmu Tuhan. Maka dengan demikian Fansuri tidak menyamakan antara Tuhan dan hambanya.

Disamping menganjur faham Wahdat al-Wujud, banyak pula faham lain yang berkembang pesat seperti faham kesatuan Tuhan dengan makhluk. Faham kesatuan antara Tuhan dan makhluk tentu berbeda dengan gagagasan kesatuan wujud (wahdat al-Wujud) Fansuri. Terhadap faham tersebut Fansuri menanggapinya tidak dengan emosional, bahkan ia lebih mentolerir terhadap ungkapan-ungkapan ekstatik (syatahat) para sufi yang mengatakan kesatuan antara diri dengan Tuhan. Seperti pernyataan al-Hallaj misalnya, bahwa dirinya adalah Tuhan (Ana al-Haq). Dalam kasus pernyataan al-Hallaj, bagi Fansuri sesungguhnya hal itu tidak boleh diucakan dan sekaligus tidak dapat dibenarkan, sebab keberadaan ia (al-Hallaj) pada saat itu dalam keadaan berahi atau mabuk dalam posisi yang fana. ${ }^{23}$ Dengan kata lain, ungkapan tersebut hanya dibenarkan pada kondisi seseorang sedang mabuk atau tidak ingat terhadap diri dan sekitarnya.

\footnotetext{
${ }^{22}$ Ibid, 134 dan Abdul Hadi W.M., Tasawuf Yang Tertindas, 153

${ }^{23}$ Oman Fathurahman, Tanbih al-Masyi, 54
}

Kariman, Volume 06, Nomor 02, Desember 2018|221 
Rasuki

Meski demikian, Fansuri tidak sepakat dengan faham ittihad dan hulul, di mana dalam kedua doktrin ini, Tuhan benar-benar immanen dan bersemayam di tempat-tempat tertentu di dalam tubuh manusia. Para pengikut atau muridmuridnya dianjurkan agar tidak terpesona dengan faham ittihad dan hulul (inkarnasi) yang telah ada dan banyak berkembang. Dalam syairnya ia menyatakan ${ }^{24}$ :

"Aho segala ummat Rasul

Tuntut 'ilmu haqiqat al-wushul

Karena 'ilmu itu pada Allah qabul

I'tiqadmu jangan ittihad dan hulul'

Faham Wahdat al-Wujud Hamzah Fansuri dengan demikian jelas berbeda dengan ajaran tasawuf yang mengajarkan tentang penyatuan Tuhan atau ingkarnasi-Nya dengan hamba mapun dengan makhluk-makhluk lainnya.

\section{Kesimpulan}

Tasawuf awal yang mengajarkan faham Wahdat al-Wujud di Indonesia pertama kali adalah hamzah Fansuri. Hal tersebut di dapatkan ketika ia melakukan perjalanan pengembaraan dalam mencari ilmu ke beberapa negara seperti Iraq, dan Makkah. Berkat perjalanan itu ia sempat bersentuhan dengan gagasan tokoh-tokoh tasawuf besar seperti al-Bustami, al-Bustami, al-Ghazali dan Ibn 'Arabi, tentang faham Wahdat al-Wujud.

Dengan pemahaman bahasa arab yang mendalam, Fansuri dapat memahami dengan baik gagasan Ibn 'Arabi khususnya faham Wahdat al-Wujud. Dengan pemahamannya tersebut akhirnya sekembalinya ketanah air (Nusanatara) Fansuri mulai mengajarkan dan mengembangkan faham Wahdat al-Wujud Ibn 'Arabi kepada masyarakat Nusantara (Sumatera Utara), yakni kepada para pengikut atau murid-muridya.

Wahdat al-Wujud adalah faham yang menjelaskan bahwa Tuhan adalah Wujud Pertama yang mengadakan akan wujud-wujud lainnya. Sebagai Wujud Pertama, Tuhan adalah entitas hakekat yang sebenarnya dan berbeda dengan wujud-wujud lainnya dimana entitas itu hanya merupakan wujud tamsil/metafor semata dari wujud Pertama, Tuhan. Sebagai wujud awal yang mencipta wujud (makhluk) keduanya bukan wujud yang menyatu sebagaimana faham hulul

\footnotetext{
${ }^{24}$ Abdul Hadi W. M., Tasawuf Yang Tertindas, 133

222 | Kariman, Volume 06, Nomor 01, Desember 2018
} 
mapun ittihad. Keduanya bukan wujud menyatu, akan tetapi sebatas penyebab adanya wujud lain dari yang pertama, Tuhan.

\section{DAFTAR PUSTAKA}

Arifin, Miftah. Sufi Nusantara: Biografi, Karya Intelektual \& Pemikiran Tasawuf, Jogjakarta: AR-RUZZ MEDIA, 2013

Drewes, G.W.J. dan LF. Brakel, The poems of Hamzah Fansuri, Bibl. Indonesia, 26, Foris Publication: Dordrecht-Hollend, 1986

Fathurahman, Oman. Tanbih al-Masyi Menyoal Wahdatul Wujud: Kasus Abdurrauf Singkel di Aceh Abad 17, Bandung: Mizan, 1999

Guillot, Claude dan Ludvik Kalus. Batu Nisan Hamzah Fansuri, Jakarta: Depbudpar, 2007

Hadi W. M., Abdul. Tasawuf Yang Tertindas, Jakarta: Paramadina, 2001

Shihab, Alwi. Islam Sufistik: "Islam Pertama" dan Pengaruhnya hingga Kini di Indonesia, Bandung: Penerbit Mizan, 2001 
Rasuki

224 | Kariman, Volume 06, Nomor 01, Desember 2018 